\title{
Venospastic phenomena of saphenous vein bypass grafts: possible causes for unexplained postoperative recurrence of angina or early or late occlusion of vein bypass grafts
}

\author{
MASSOUD MALEKI, JACK C MANLEY \\ From St Luke's Hospital and the Cardiology Division, Medical College of Wisconsin, Milwaukee, Wisconsin, \\ USA
}

SUMMARY Angina recurred in a 54 year old white man after multivessel coronary artery bypass surgery. Fourteen months after operation the frequency and intensity of his mixed angina increased and cardiac stress testing was positive. Repeat cardiac catheterisation showed that all the bypass grafts were widely patent; however, spasms of a vein graft to right coronary artery system were clearly seen. Treatment with calcium blocking agents and long acting nitrates abolished the symptoms during 16 months of clinical follow up.

Coronary artery vasospasm is seen in about 3\% of patients undergoing coronary arteriography ${ }^{1}$ and interest in this entity is growing. ${ }^{2}$ Spasm may occur in normal vessels and those that are mildly or severely diseased and in patients with no symptoms or with severe disabling angina at rest.

Spasm was seen during and soon after operation in aortocoronary vein bypass grafts in two cases. ${ }^{34}$ To our knowledge confirmed, symptomatic, late, and chronic saphenous vein bypass graft venospasm has not been described before. In this report we present an interesting and rather unusual case of spasm in an aortocoronary vein bypass graft in a patient in whom mixed angina (pain at rest and during effort in the left shoulder and left neck) developed postoperatively with intensification of symptoms about 14 months after coronary artery bypass operation.

\section{Case report}

A 54 year old white man underwent coronary artery

Requests for reprints to Dr Massoud Maleki, Euclid Medical Building, 3201 South 16th Street, Milwaukee, Wisconsin 53215, USA. bypass surgery on 10 January 1983, because of considerable angina and positive stress testing. $\mathrm{He}$ received a left internal mammary artery anastomosis to the left anterior descending artery, a vein bypass graft to the first major diagonal division, a sequential vein graft side-to-side to the second marginal and end-to-side to the third marginal division of the circumflex system, and an additional sequential vein graft, side-to-side to the posterior descending branch and end-to-side to the distal right branch of the right coronary artery system.

His intraoperative and immediate postoperative course was uneventful. He remained free of symptoms except for occasional episodes of vague discomfort in the left shoulder and chest that was often unrelated to effort.

In March 1984 he began to experience increasing episodes of pain in the left shoulder and left neck at rest and on mild physical effort. In July 1984, while at work, he experienced three episodes of pain in the left neck and shoulder with radiation to the upper left arm and two episodes of a feeling of pressure under the lower sternum and numbness and tingling of the fingers of the left hand. These episodes occurred 


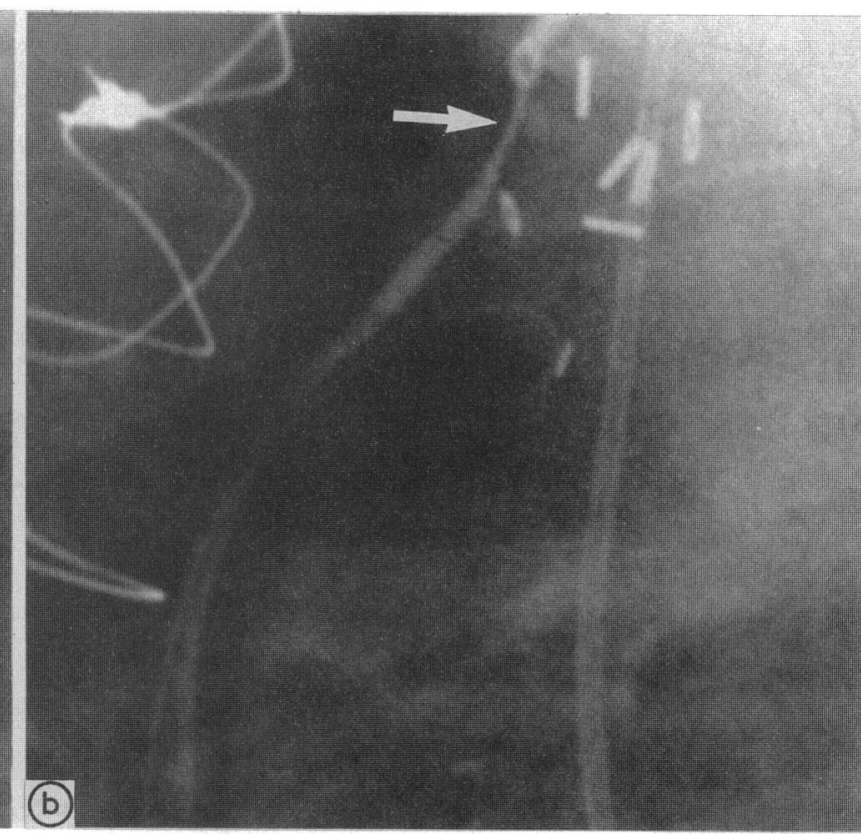

Fig 1 (a) Vein bypass graft to right coronary artery showing severe spasm of its most proximal segment (arrowed) and slow distal run off (asterisk). (b) Vein bypass graft to right coronary artery system during subsequent cardiac catheterisation showing further proximal vein graft spasm (arrow).

during his usual daily walking activities at his supervisory job. During one episode he became sweaty and dizzy.

He was seen in the emergency room but there was no evidence of myocardial infarction or ischaemia. Cardiac stress testing caused the development of pain in the left shoulder and left neck and extrasystoles at 9.6 metabolic equivalents without associated typical ischaemic changes in the ST segment.

Repeat cardiac catheterisation and coronary angiography on 10 July 1984 showed widely patent vein bypass grafts to the marginal divisions of the circumflex coronary artery and to the diagonal branch of the left anterior descending coronary artery as well as a patent left internal mammary artery graft to the left anterior descending vessel. There was no evidence of progression of atherosclerosis in the native left coronary artery system.

In the sequential vein graft to right coronary artery system there was a $95 \%$ segmental stenosis in the 1.5 $\mathrm{cm}$ most proximal segment with very slow filling of the distal segment of this vein graft (Fig 1a). In addition, the side-to-side arm of this vein graft anastomosis to the posterior descending branch of the right coronary artery was totally occluded. The end-to-side anastomosis to a large distal right branch of the right coronary artery, however, was widely patent with good anterograde visualisation of this native vessel. The posterior descending branch of the right coronary artery was also well visualised on anterograde injection of contrast into the native right coronary artery, which showed about $40-50 \%$ stenosis in its midsegment and total occlusion of the distal right branch at its origin just before the end-to-side anastomosis of its respective vein graft.

The patient was then considered for percutaneous transluminal angioplasty of the proximal portion of the vein graft to this large distal right branch of the right coronary artery.

On 22 August 1984 he was taken to the cardiac catheterisation laboratory where initial subselective injection into the vein graft to the right coronary artery once again showed a long segmental stenosis on the most proximal portion of this vein graft with $80-90 \%$ luminal reduction. (Fig $1 \mathrm{~b}$ ). The appearance after the second injection suggested a dynamic component to the stenosis, so we gave additional sublingual glyceryl trinitrate and nifedipine.

Subsequent injection into this vein graft, in right and left anterior oblique views, showed a widely patent proximal vein graft with no evidence of any important stenosis (fig 2).

We concluded that the stenosis was caused solely by venospasm, and angioplasty was not attempted on this vein graft. We then proceeded with the introduction of the balloon dilatation catheter into the native right coronary artery and this catheter was negotiated 


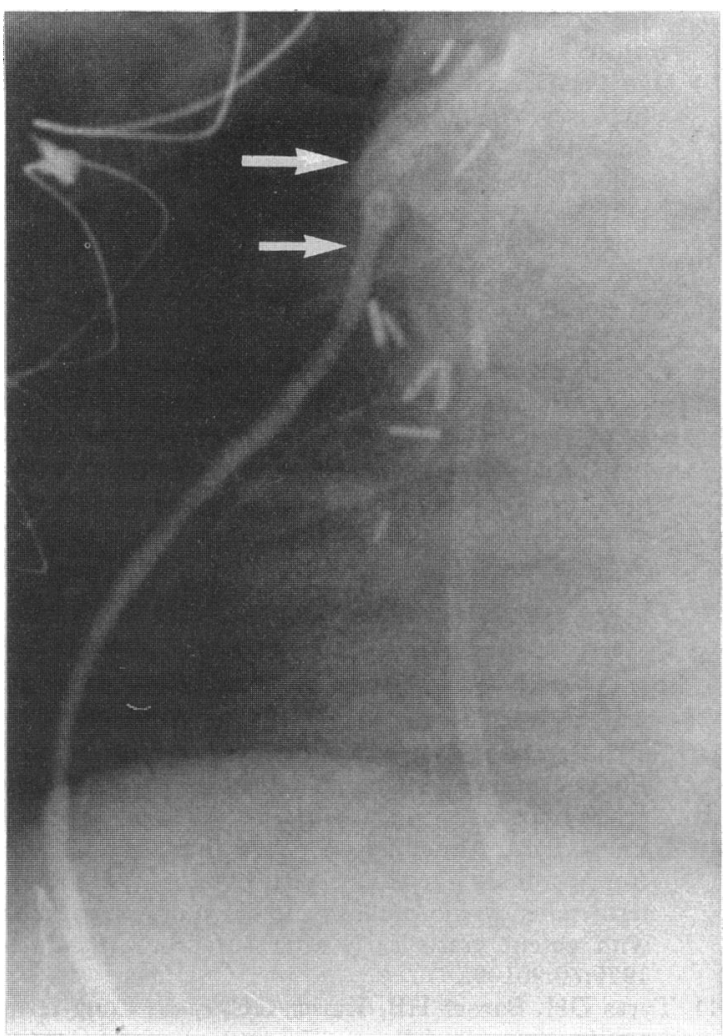

Fig 2 Vein bypass graft to right coronary artery in left and right anterior oblique projections after administration of sublingual nifedipine and glyceryl trinitrate, showing a return to normal at the site of spasm of the vein bypass graft (small arrow) after subselective dye injections (large arrow).

across the stenotic segment of the mid portion of the native right coronary artery over a steerable guide wire system. Simultaneous pressure recordings were obtained distal and proximal to the stenotic region; they did not show any gradient.

Because we did not regard the stenosis of the mid right coronary artery as haemodynamically important, angioplasty was not performed. At discharge the patient was taking $80 \mathrm{mg}$ of nifedipine and $40 \mathrm{mg}$ of isosorbide dinitrate in divided doses. The patient remained symptom free during a clinical follow up of 16 months.

\section{Discussion}

Long term follow up reports on patients who have undergone coronary artery bypass operation with saphenous vein grafts showed early and late recurrences of symptoms in many. ${ }^{5-7}$ These ischaemic symptoms might be caused by disease progression in the grafted and non-grafted vessels, incomplete revascularisation, graft occlusion, ath- erosclerotic stenosis of a vein bypass graft, technical problem at the heel or toe of the vein graft anastomosis, kinking of the vein graft, and spasm of the saphenous vein bypass graft. . $^{-11}$

In two earlier cases spasm of the saphenous bypass graft occurred in freshly resected or relatively new and young saphenous veins that contained viable and reactive smooth muscle cells within the media. ${ }^{34} \mathrm{We}$ found spasm in an older vein graft that was not expected to contain reactive smooth muscle cells and apparently was a rigid non-reactive conduit. ${ }^{12-14}$ This case underlines the fact that the degree and timing of changes in the media of the vein graft can vary and that such variation could allow severe, symptomatic venospasm and recurrence of disabling angina or myocardial infarctions to develop as a result of graft closure. Within a month of operation, vein grafts show inflammatory cell infiltration and variable necrosis of smooth muscle cells in the media. After six months, these grafts show a considerable decrease in the number of smooth muscle cells in the media, which are replaced with fibrous tissue and collagen. Thus the saphenous vein bypass graft becomes stiffer and more fibrous. The degree of these changes varies from one patient to another, from one graft to another in the same patient, and from one segment to another in the same graft. ${ }^{12-14}$ After six months, the contractility of these grafts is much reduced. ${ }^{15} 16$ So severe spasm of vein graft after the first six months seems unlikely. But our case indicates that severe symptomatic spasm might occur even in older vein bypass grafts despite these histological changes.

Any attempt to explain and understand this unique phenomenon can only be based on the mechanisms suggested for spasm in native coronary arteries. Melville et al suggested that coronary spasm is caused by neural impulses from the central nervous system or autonomic nervous system. ${ }^{17}$ This hypothesis, however, has been challenged by the results of autotransplantation reported by Clark et al. ${ }^{18}$ They described severe refactory coronary arterial spasm in a patient with a cardiac transplant. Although this patient became symptom free after transplantation, right coronary artery spasm was provoked by infusion of ergometrine.

It seems, therefore, that coronary spasm can occur in a totally denervated heart. In vivo and in vitro studies showed that vascular tone is balanced by two potent hormones released from platelets and endothelial cells. Thromboxane $\mathrm{A}_{2}$, released by the platelets, is a powerful vasoconstrictor that has been implicated in coronary artery spasm and genesis of atherosclerosis and early postoperative occlusion of vein bypass grafts. Prostacyclin, a powerful vasodilatating prostaglandin released from endothelial cells, counters the effect of thromboxane $A_{2}$ to 
maintain a balanced vascular tone. When the concentration of thromboxane $A_{2}$ is higher than that of prostacyclin, vasoconstriction may occur. ${ }^{1920}$ Platelet aggregation could result in further increase in thromboxane $A_{2}$ which in turn may precipitate further spasm, diminished flow, and further aggregation leading ultimately to thrombosis and early postoperative occlusion of vein bypass grafts.

In this case report, there was evidence of some progression of disease in the native right coronary artery. This, however, was not regarded as haemodynamically important in reducing resting coronary flow because there was no pressure drop across the stenosis. Nevertheless, such stenosis may affect maximal flow to such an extent that coronary flow reserve is reduced and symptoms develop on effort.

This patient's symptoms, however, were often unrelated to effort, and in view of the clear demonstration of the spasm of vein graft in two successive studies and the success of treatment with calcium blocking agents and nitrates on the patient's symptoms, we believe that the spontaneous spasm of the vein bypass graft was probably responsible for the patient's symptoms by reducing blood flow to a large distal right branch of the right coronary artery, which was totally occluded proximally to the site of an endto-side anastomosis of a vein bypass graft.

Stress testing was also subjectively positive; however, his symptoms of shoulder and neck pain with radiation to the left arm during the stress testing were identical to his usual presenting symptoms. We therefore believed that his stress testing, although electrocardiographically silent, represented myocardial ischaemia.

Mechanical vasospasm related to diagnostic catheterisation also seems unlikely because the initial vein graft injections were performed subselectively.

The findings in this case may be an example of a feature that is more common than is generally realised. It may help to explain intraoperative or immediate postoperative deterioration in some patients who have undergone coronary artery bypass operation. It may also be one of the mechanisms responsible for postoperative closure of the vein bypass graft.

\section{References}

1 Chahine RA, Raizner AE, Ishimori T, Luchi RJ, McIntosh HD. The incidence and clinical implications of coronary artery spasm. Circulation 1975;52:972-8.

2 Lown B, DeSilva $R$. Is coronary arterial spasm a risk factor for coronary atherosclerosis? Am J Cardiol 1980;45:901-3.

3 Victor MF, Kimbiris D, Iskandrian AS, et al. Spasm of a saphenous vein bypass graft. A possible mechanism for occlusion of the venous graft. Chest $1981 ; 80$ : 413-5.

4 Dye TE, Gregor P, Murphy TF. Acute spasm of vein bypass graft and recipient artery in the immediate postoperative period. Texas Heart Institute Journal 1984;11:198-203.

5 Lawrie GM, Morris GC Jr, Howell JF, et al. Results of coronary bypass more than five years after operation in 434 patients. Clinical, treadmill exercise and angiographic correlations. Am J Cardiol 1977; 40:665-72.

6 Lie JT, Lawrie GM, Morris GC Jr. Aortocoronary bypass saphenous vein graft atherosclerosis: anatomic study of 99 vein grafts from normal and hyperlipoproteinemic patients to 75 months postoperatively. Am J Cardiol 1977;40:906-14.

7 Seides SF, Borer JS, Kent KM, et al. Long-term ! anatomic fate of coronary artery bypass grafts and functional studies of patients five years after operation. N Engl J Med 1978;298:1213-7.

8 Vouhe P, Grondin CM. Reoperation for coronary graft failure: clinical and angiographic results in 43 patients. Ann Thorac Surg 1979;27:328-34.

9 Guthaner DF, Robert EW, Alderman EL, Wexler L. Long term serial angiographic studies after coronary artery bypass surgery. Circulation 1979;60:250-9.

10 Hamby RI, Aintablian A, Handler $M$, et al. Aortocoronary saphenous vein bypass grafts: longterm, patency, morphology and blood flow in patients with patent grafts early after surgery. Circulation 1979;60:901-9.

11 Tyras DH, Barner HB, Kaiser GC, et al. Long-term results of myocardial revascularization. Am J Cardiol 1979;44:1290-6.

12 Fuchs JCA, Mitchener JS III, Hagen PO. Postoperative changes in autologous vein grafts. Ann Surg 1978;188:1-15.

13 Spray TL, Roberts WC. Changes in saphenous veins used as aortocoronary bypass grafts. Am Heart J 1977;94:500-16.

14 Jones M, Donkle DM, Ferrans VJ, et al. Lesions observed in arterial autogenous vein grafts: light and electron microscopic evaluation. Circulation 1973;57 and 58 (suppl III):198-210.

15 Waddell WB, Vogelfanger IJ, Bosc M, et al. Changes in contractility, compliance and elasticity in experimental arterial vein-autografts. Can J Surg 1973;16: 252-60.

16 Heupler FA Jr, Proudfit WL, Razavi M, et al. Ergonovine maleate provocative test for coronary arterial spasm. Am J Cardiol 1978;41:631-40.

17 Melville K, Garvey H, Shister E, et al. Central nervous system stimulation and cardiac ischemic changes in monkeys. Ann NY Acad Sci 1969;156:241-60.

18 Clark DA, Quint RA, Mitchell RL, Angell WW. Coronary artery spasm. J Thorac Cardiovasc Surg 1977;73:332-9.

19 Conti CR, Pepine CJ, Curry JC Jr. Coronary artery spasm: an important mechanism in the pathophysiology of ischemic heart disease. Curr Probl Cardiol 1979;4:9-70.

20 Dusting GJ, Chapple DJ, Hughes R, et al. Prostacyclin $\left(\mathrm{PGI}_{2}\right)$ induces coronary vasodilitation in anesthetized dogs. Cardiovasc Res 1978;12:720-30. 